\title{
Development of a functional dairy food: exploring bioactive and preservation effects of chamomile (Matricaria recutita L.)
}

Cristina Caleja $^{1,2}$, Lillian Barros ${ }^{1}$, Amilcar L. Antonio ${ }^{1}$, Ana Ciric ${ }^{3}$, João C.M.

Barreira $^{1,2}$, Marina Sokovic ${ }^{3}$, M. Beatriz P.P. Oliveira ${ }^{2}$, Celestino Santos-Buelga ${ }^{4}$, Isabel C.F.R. Ferreira ${ }^{1, *}$

${ }^{1}$ Mountain Research Centre (CIMO), ESA, Polytechnic Institute of Bragança, Portugal. ${ }^{2}$ REQUIMTE - Science Chemical Department, Faculty of Pharmacy, University of Porto, Portugal.

${ }^{3}$ University of Belgrade, Department of Plant Physiology, Institute for Biological Research “Siniša Stankovič”, Bulevar Despota Stefana 142, 11000 Belgrade, Serbia. ${ }^{4}$ GIP-USAL, Faculty of Pharmacy, University of Salamanca, Campus Miguel de Unamuno, 37007 Salamanca, Spain.

* Author to whom correspondence should be addressed (e-mail: iferreira@ipb.pt telephone +351-273-303219; fax +351-273-325405). 


\begin{abstract}
The antioxidant (free radical scavenging activity, reducing power and lipid peroxidation inhibition) and antimicrobial (against bacteria and fungi) potential of Matricaria recutita L. (chamomile) extracts obtained by decoction was demonstrated. The characterization of the extracts highlighted dicaffeoyl-2,7-anhydro-3-deoxy-2octulopyranosonic acid (diCDOA) and luteolin- $O$-glucuronide as the main phenolic compounds. Extracts containing these natural ingredients were incorporated into cottage cheese, and the prepared products were compared with samples incorporated with chamomile powder and plain cottage cheese (control). Nutritional composition, colour and antioxidant activity of all samples were evaluated along storage time. Chamomile decoctions (natural bioactive ingredient) did not alter significantly the nutritional and fatty acids profiles of cottage cheese, but improved its antioxidant potential, independent of the storage time. Moreover, it increased the shelf life since only the control samples showed signs of degradation after 14 days of storage. The development of this novel functional dairy product emphasizes the bioactive and preservation potential of chamomile.
\end{abstract}

Keywords: Functional food; Cottage cheese; Matricaria recutita; Antioxidant/antimicrobial properties; Natural preservative. 


\section{Introduction}

Novel functional foods with health promoting natural ingredients instead of synthetic additives have been intensively developed and commercialized by food industry (Carocho, Barreiro, Morales \& Ferreira, 2014; Caleja et al., 2015). Furthermore, there is an increasing concern among consumers to seek healthier and "natural" foods to avoid a series of food safety risks that have become a global problem (Sarig et al., 2003). Food additives are widely used for various purposes in order to improve the appearance, flavour, colour, texture or shelf life of the food, making this the most desirable form to the consumers' eyes. However, several studies have shown that consumption in excess can be harmful to health due to some toxicity effects (Randhawa \& Bahna, 2009; Carocho et al., 2014).

There is a tendency for consumers to choose minimally processed foods instead of processed ones, or with minimum incorporation of synthetic additives, which are being passed over by natural ones. Natural additives include compounds or extracts from plants used to improve the qualities of food. One of the most studied effects of these additives is the antioxidant activity (Rasooli, 2007). Besides the importance of antioxidants as natural conservation ingredients, these compounds/extracts can also bring bioactive properties to food. Natural extracts rich in phenolic compounds arise as promissory alternatives to plant essential oils that, sometimes, could display toxic effects (Zapata \& Smagghe, 2010; Assis, Gondim, Siqueira \& Câmara, 2011). Furthermore, due to their antioxidant properties, these molecules have been related with the prevention of ageing and various diseases related with oxidative stress, such as coronary heart disease, cancer or neurodegenerative diseases (Procházková, Bousová \& Wilhelmová, 2011; Weng \& Yen, 2012).

Chamomile (Matricaria recutita L.) is a source of phenolic compounds, such as 
flavonoids, that are the main compounds contributing to its antioxidant properties (Mulinacci, Romani, Pinelli, Vincieri \& Prucher, 2000; Nováková, Vildová, Mateus, Gonçalves \& Solich, 2010; Lin \& Harnly, 2012; Raal, Orav, Püssa, Valner, Malmiste \& Arak, 2012; Guimarães et al., 2013; Matić, Juranić, Savikin, Zdunić, Nadvinski \& Godevac, 2013; Roby, Sarhan, Selim \& Khalel, 2013; Avula et al., 2014; Zielinski Haminiuk, Alberti, Nogueira, Demiate \& Granato, 2014; Xie, Wang \& Shi, 2014). Moreover, it has been used for its many beneficial health effects as antimicrobial, neuroprotective, anti-allergic, anti-inflammatory, and anticancer agent (Alanís, Calzada, Cervantes, Torres \& Ceballos, 2005; Ranpariya, Parmar, Sheth \& Chandrashekhar, 2011; Chandrashekhar et al., 2011; Bulgari et al., 2012; Silva, Barbosa, Seito \& Fernandes, 2012; Matić et al., 2013).

Goat cheese is highly appreciated for its nutritional value, good digestibility and low allergenic properties. In addition, goat milk has been associated with certain therapeutic values in human nutrition (Haenlein, 2004; Díaz-Castro et al., 2012).

In the present work, the antioxidant and antimicrobial effects of chamomile ( $M$. recutita) were explored, developing a functional dairy food with improved preservation and bioactive properties. Therefore, natural ingredients based in chamomile phenolic compounds extracts obtained by decoction were prepared, characterized and incorporated in cottage cheese. Besides these aqueous extracts, chamomile powder was also used to functionalize different samples. The effects on nutritional value, shelf life and bioactive properties of the control and the functionalized samples were comprehensively evaluated.

\section{Materials and methods}

\subsection{Standards and reagents}

HPLC-grade acetonitrile was obtained from Merck KgaA (Darmstadt, Germany). 
Formic and acetic acids were purchased from Prolabo (VWR International, France). 2,2Diphenyl-1-picrylhydrazyl (DPPH) was obtained from Alfa Aesar (Ward Hill, MA, USA). Phenolic standards were from Extrasynthèse (Genay, France). The fatty acids methyl ester (FAME) reference standard mixture 37 (standard 47885-U) was purchased from Sigma (St. Louis, MO, USA), as also other individual fatty acid isomers, Lascorbic acid, organic acid and sugar standards, trolox (6-hydroxy-2,5,7,8tetramethylchroman-2-carboxylic acid) and positive controls, streptomycin, ampicillin, bionazole and ketokonazole. Mueller-Hinton agar (MH) and malt agar (MA) were obtained from the Institute of Immunology and Virology, Torlak (Belgrade, Serbia). Water was treated in Milli-Q water purification system (TGI Pure Water Systems, Greenville, SC, USA).

\subsection{Chamomile-based natural ingredients}

\subsubsection{Preparation}

Commercial samples of Matricaria recutita L. (chamomile) were provided by Américo Duarte Paixão Lda. (Alcanede, Portugal). The dried samples were powdered ( 20 mesh) and submitted to decoction in order to obtain phenolic-enriched extracts. The decoction was performed by adding $1 \mathrm{~g}$ of plant material to $200 \mathrm{~mL}$ of distilled water, heated (heating plate, VELP Scientific, Usmate, Italy) and boiled for $5 \mathrm{~min}$. The mixture was left to stand for $5 \mathrm{~min}$, filtered, and then frozen and lyophilized (FreeZone 4.5, Labconco, Kansas City, MO, USA).

\subsubsection{Characterization in phenolic compounds}

Phenolic compounds were determined in the decoctions by HPLC (Hewlett-Packard 1100, Agilent Technologies, Santa Clara, CA, USA), as previously described by the 
authors (Barros et al., 2013). Double online detection was carried out in a diode array detector (DAD) using 280 at $370 \mathrm{~nm}$ as preferred wavelengths and a mass spectrometer (MS) connected to the HPLC system via the DAD cell outlet. The phenolic compounds were identified by comparing their retention time, UV-vis and mass spectra with those obtained from standard solutions, when available. Otherwise, peaks were tentatively identified comparing the obtained information with available data reported in the literature. The results are expressed in $\mathrm{mg} / \mathrm{g}$ of lyophilized decoction.

\subsubsection{Antioxidant properties}

The lyophilized decoctions were re-dissolved in water $(5 \mathrm{mg} / \mathrm{mL})$ and successively diluted until determination of $\mathrm{EC}_{50}$ values (sample concentration providing $50 \%$ of antioxidant activity or 0.5 of absorbance in the reducing power assay).

DPPH radical-scavenging activity and reducing power were evaluated using ELX800 microplate Reader (Bio-Tek Instruments, Inc., Winooski, VT, USA) at 515 and $690 \mathrm{~nm}$, respectively. $\beta$-Carotene bleaching and lipid peroxidation (thiobarbituric acid reactive substances, TBARS) inhibition were evaluated spectrophotometrically at 470 and 532 $\mathrm{nm}$, respectively. The complete protocols were previously described by the authors (Barros et al., 2013). Trolox was used as positive control in all the assays.

\subsubsection{Antimicrobial properties}

Antibacterial activity was evaluated against Gram-negative bacteria: Escherichia coli (ATCC 35210), Pseudomonas aeruginosa (ATCC 27853), Salmonella typhimurium (ATCC 13311), Enterobacter cloacae (ATCC 35030), and Gram-positive bacteria: Staphylococcus aureus (ATCC 6538), Bacillus cereus (clinical isolate), Micrococcus flavus (ATCC 10240), and Listeria monocytogenes (NCTC 7973), following the 
procedure previously described by the authors (Sokovic, Glamočlija, Marin, Brkić \& van Griensven, 2010). The minimum inhibitory (MIC) and minimum bactericidal (MBC) concentrations were determined following the same reference. Streptomycin and ampicillin were used as positive controls. Antifungal activity was evaluated against Aspergillus fumigatus (ATCC 1022), Aspergillus ochraceus (ATCC 12066), Aspergillus versicolor (ATCC 11730), Aspergillus niger (ATCC 6275), Penicillium funiculosum (ATCC 36839), Penicillium ochrochloron (ATCC 9112), Penicillium verrucosum var. cyclopium (food isolate), and Trichoderma viride (IAM 5061), following the procedure previously described by the authors (Sokovic \& van Griensven, 2006). The minimum inhibitory (MIC) and minimum fungicidal (MFC) concentrations were determined following the same reference. Bionazole and ketokonazole were used as positive controls.

\subsection{Development of the functional food}

2.3.1. Preparation of cottage cheese by incorporation with chamomile-based natural ingredients

All the samples of cottage cheese were prepared by "Queijos Casa Matias Lda." (one of the main producer companies of "Serra da Estrela" cheese; being the latter the most famous Portuguese cheese). Three groups of samples were prepared (cottage cheeses with $250 \mathrm{~g}$ ): control samples (cottage cheese without the chamomile-based natural ingredient); samples with the chamomile decoction (it was incorporated in cottage cheese at $\mathrm{EC}_{25}$ value previously determined by $\mathrm{DPPH}$ assay: $0.165 \mathrm{mg} / \mathrm{mL}$, corresponding to $0.495 \mathrm{~g}$ for each $250 \mathrm{~g}$ cottage cheese sample); and samples with the chamomile powder (it was incorporated at $0.644 \mathrm{mg} / \mathrm{mL}$, considering the decoction yield of $25.6 \%$, corresponding to $1.932 \mathrm{~g}$ for each $250 \mathrm{~g}$ cottage cheese sample). 
Samples corresponding to each group were pooled together and further divided in three subgroups, which were submitted to individual extraction procedures.

\subsubsection{Evaluation of nutritional composition, colour and antioxidant activity along} storage time

The samples (three different cottage cheeses for each storage time) were submitted to an evaluation of nutritional composition, colour and antioxidant activity, immediately after the incorporations and after 7 and 14 days of storage at $4{ }^{\circ} \mathrm{C}$.

The samples were analyzed for proximate composition (moisture, protein, fat, carbohydrates and ash) using the AOAC (2005) procedures. The crude protein content $(\mathrm{N} \times 6.38)$ of the samples was estimated by Kjeldahl method; the crude fat was determined by extracting a known weight of powdered sample with petroleum ether, using a Soxhlet apparatus; the ash content was determined by incineration at $600 \pm 15^{\circ} \mathrm{C}$. Total carbohydrates were calculated by difference. Total energy was calculated according to the following equation: Energy $(\mathrm{kcal})=4 \times(\mathrm{g}$ proteins $+\mathrm{g}$ carbohydrates $)$ $+9 \times($ g lipids $)$.

Fatty acids, free sugars and organic acids were determined by gas-chromatography coupled to flame ionization detector (GC-FID), HPLC coupled to a refraction index (RI) detector, and HPLC coupled to a photodiode array detector (PDA) at $215 \mathrm{~nm}$ and 245 nm (for ascorbic acid), respectively, according to previous analytical validation and detailed description by the authors (Barros et al., 2013). Fatty acids were identified by comparison with standards and the results were expressed in relative percentage of each fatty acid. Free sugars were identified by comparison with standards, and further quantified ( $\mathrm{g} / 100 \mathrm{~g}$ of cottage cheese) by using the internal standard (melezitose). Organic acids were identified and quantified ( $\mathrm{g} / 100 \mathrm{~g}$ of cottage cheese) by using 
calibration curves from commercial standards.

The colour of the samples was measured in three different points, for each sample, by using a colourimeter (model CR-400, Konica Minolta Sensing Inc., Tokyo, Japan). Using the illuminant $\mathrm{C}$ and diaphragm aperture of $8 \mathrm{~mm}$, the CIE $L^{*} a^{*} b^{*}$ colour space values were registered using a data software "Spectra Magic Nx" (version CM-S100W 2.03.0006) (Fernandes, Antonio, Barreira, Oliveira, Martins \& Ferreira, 2012).

For evaluation of antioxidant activity, the samples were submitted to DPPH and reducing power assays, previously mentioned.

\subsection{Statistical analysis}

All the experiments were performed using three independent samples, being three different extracts obtained from each sample $(n=9)$ and all the assays were carried out in triplicate. In the assessment of differences among antimicrobial assays, results were evaluated using 1-way ANOVA. The homogeneity of variance, was tested by means of the Levene's tests. All dependent variables were compared using Tukey's honestly significant difference (HSD) or Tamhane's T2 multiple comparison tests, when homoscedasticity was verified or not, respectively.

Regarding the evaluation of the effects of functionalizing agent and storage time, an analysis of variance (ANOVA) with type III sums of squares was performed using the Repeated Measures Analysis procedure of the General Linear Model. Since the independence of variables could not be assumed, it was need to verify the sphericity criterion, which evaluates if the correlation between treatments is the same, assuming that variances in the differences among conditions are the same. Sphericity was evaluated trough the Mauchly's test; every time the sphericity assumption was violated, the Greenhouse-Geisser correction was applied. A 2-factor $\times 3$-levels matrix was studied. 
All the statistical analysis were carried out using SPSS v. 22.0 program (IBM Corp., Armonk, NY, USA).

\section{Results and discussion}

3.1. Chemical characterization, antioxidant and antimicrobial properties of chamomile phenolic-enriched extracts

Up to nineteen phenolic compounds, including phenolic acids and flavonoids were detected in the $M$. recutita decoctions (Table 1).

Protocatechuic acid (compound 2), 5-O-caffeolylquinic acid (compound 3), caffeic acid (compound 5), myricetin-3-O-glucoside (compound 6), quercetin-3-O-glucoside (compound 8), luteolin-7-O-glucoside (compound 9), apigenin-7-O-glucoside (compound 15) and apigenin (compound 18) were positively identified by comparison of their retention time, mass and UV-vis characteristics with commercial standards. Most of these compounds have been previously described in $M$. recutita samples by different authors (Mulinacci et al., 2000; Nováková et al., 2010; Lin \& Harnly, 2012; Raal et al., 2012; Guimarães et al., 2013; Matić et al., 2013; Avula et al., 2014; Zielinski et al., 2014; Xie et al., 2014).

Compounds 1 ([M-H] $]^{-}$at $m / z$ 341) yielded a fragment at $\mathrm{m} / z 179$ (caffeic acid) from the loss of $162 \mathrm{mu}$ (hexosyl moiety), which allowed the tentative identification as caffeic acid hexoside. Compounds 11 and 12 were identified as cis and trans isomers of 3,5-Odicaffeoylquinic acids, respectively. These compounds presented a similar fragmentation pattern to the ones previously reported by Guimarães et al. (2013). MS ${ }^{2}$ base peak was at $m / z 353$, produced by the loss of one of the caffeoyl moieties [M-Hcaffeoyl] ${ }^{-}$, and subsequent fragmentation of this ion yielded the same fragments as 5caffeoylquinic acid at $\mathrm{m} / \mathrm{z} 191,179$ and 135 , although in this case with a comparatively 
more intense signal at $\mathrm{m} / z 179$ [caffeic acid-H]'. Furthermore, cis hydroxycinnamoyl derivatives elute before the corresponding trans ones, as observed after UV irradiation (366 nm, $24 \mathrm{~h}$ ) of hydroxycinnamic acids in our laboratory, justifying the elution order of these isomers. These and other dicaffeoylquinic derivatives have been previously reported in flowers of $M$. recutita (Nováková et al., 2010; Lin \& Harnly, 2012; Raal et al., 2012; Guimarães et al., 2013).

Compounds 4, 13, 14 and 19 were tentatively assigned as caffeoyl-2,7-anhydro-3deoxy-2-octulopyranosonic acids (CDOA) derivatives (Figure 1) owing to the previous identification of compounds with similar UV and mass spectra characteristics in other members of the Asteraceae familiy, such as Erigeron breviscapus (vant.) Hand. Mazz. (Zhang, Shi, Qu, \& Cheng, 2007; Zhang, Zhao, Ma, Wu, \& Zeng, 2010; Liao et al., 2010) and Chamaemelum nobile (L.) (Zhao et al., 2014). To the best of our knowledge, such type of compounds has not been previously reported in $M$. recutita flowers.

Compound 4 showed a pseudomolecular ion $[\mathrm{M}-\mathrm{H}]^{-} \mathrm{m} / \mathrm{z}$ at 381 coherent with a monoCDOA. Three different derivatives are possible, i.e., 3-CDOA, 4-CDOA and 9-CDOA (Figure 1), from which a tentative identity of 3-CDOA has been assigned taking into account its elution before the caffeic as observed by Zhang et al. (2007) and Liao et al. (2010). Compounds 13 and 14 possessed the same pseudomolecular ion ([M-H] $\mathrm{m} / \mathrm{z}$ at 543) and fragmentation patterns that allowed their identification as diCDOA. Two compounds with similar characteristics were also detected in E. breviscapus samples (Zhang et al., 2007, 2010; Liao et al., 2010), which were respectively identified as erigoster B (3,9-diCDOA) and 4,9-diCDOA (or 3,4 diCDOA), so that those identities were tentatively assumed for the compounds observed in our case. The pseudomolecular ion of compound $19\left([\mathrm{M}-\mathrm{H}]^{-} \mathrm{m} / \mathrm{z}\right.$ at 705$)$ could be associated to 3,4,9triCDOA (Zhang et al., 2007, 2010) or to a diCDOA glucoside, as reported by Liao et 
al. (2010). In our case, an identity as 3,4,9-triCDOA was assumed taking into account that for the diCDOA glucoside an elution earlier to the diCDOAs should be expected due to its greater polarity.

The four remaining compounds $(7,10,16$ and 17) corresponded to flavonoids. UV and mass spectra of compound $17\left([\mathrm{M}-\mathrm{H}]^{-}\right.$at $\left.\mathrm{m} / \mathrm{z} 473\right)$ allowed its identification as apigenin 7-O-acetylglucoside, a compound consistently reported in $M$. chamomilla flowers (Kunde \& Isaac, 1979; Pietta, Manera, \& Ceva, 1987; Svehlikova et al., 2004; Weber, Herrmann, Hartmann, Joppe, Schmidt \& Heinz-Jürgen, 2008; Lin \& Harnly, 2012; Raal et al., 2012; Avula et al., 2014; Xie et al., 2014). Peak 10 presented a pseudo molecular ion $[\mathrm{M}-\mathrm{H}]^{-}$at $m / z 461$, releasing a fragment at $\mathrm{m} / \mathrm{z} 285$ ([M-176] $]^{-}$(loss of a glucuronyl moiety). These characteristics and also its UV spectrum $\left(\lambda_{\max }\right.$ at $\left.348 \mathrm{~nm}\right)$ suggest that it could correspond to a luteolin $O$-glucuronide. As far as we know, that compound has not been cited in $M$. recutita, although luteolin glycosides are usually found in relevant amounts in chamomile flowers and infusions (Mulinacci et al., 2000; Atoui, Mansouri, Boskou \& Kefalas, 2005; Nováková et al., 2010; Raal et al., 2012; Haghi, Hatami, Safaei \& Mehran, 2014; Guimaraes et al., 2013; Avula et al., 2014). Compounds 7 and 16 presented pseudomolecular ions $[\mathrm{M}-\mathrm{H}]^{-}$at $\mathrm{m} / \mathrm{z} 639$ and 519 releasing two common $\mathrm{MS}^{2}$ fragments at $m / z 315$ ([M-H-162-162] and [M-H-42-162] $]^{-}$, loss of dihexosyl and acetylhexoside moieties, respectively) and $300 \mathrm{~m} / \mathrm{z}$ ([M-H-15]', loss of a methyl moiety), pointing to they are methyl-quercetin glycosides. The presence of isorhamnetin (i.e., 3'-O-methylquercetin) derivatives in $M$. recutita flowers has been indicated by some authors (Kunde \& Isaac, 1979; Nováková et al., 2010; Haghi et al., 2014), so that a tentative identity as isorhamnetin- $O$-dihexoside and isorhamnetin- $O$-acetylhexoside has been assumed for peaks 7 and 16, respectively. In our knowledge, such compounds have not been reported in $M$. recutita. 
The decoctions of $M$. recutita presented a higher content in phenolic acids than flavonoids, being a diCDOA (tentatively identified as 4,9-diCDOA or 3,4 diCDOA) the most abundant compound present and luteolin- $O$-glucuronide the most abundant flavonoid.

Matić et al. (2013) presented results for infusions and decoctions of M. recutita, in terms of area at $356 \mathrm{~nm}$, therefore, it cannot be compared to our study, but nevertheless, two ferulic acid glucosides were the compounds with the highest area. Lin and Harnly (2012) and Mulinacci et al. (2000) did not present quantification data. The phenolic acid, 5-O-caffeolylquinic acid was the most abundant compound in $M$. recutita flowers studied by Zielinski et al. (2014) and Nováková et al. (2010). The latest authors also presented apigenin-7-O-glucoside as the most abundant flavonoid. Raal et al. (2012) presented quantification results for infusions of Chamomilla recutita of different commercial samples, packaged in different countries; these results were presented in $\mathrm{mg} / 200 \mathrm{~mL}$. Of the thirteen compounds identified, a ferulic acid glucoside was the major compound found. Avula et al. (2014) studied extracts of Matricaria chamomilla L. (Syn. M. recutita L.), identifying nine phenolic compounds and being cis GMCA [(Z)-2- $\beta$-D-glucopyranosyloxy-4-methoxycinnamic acid] the major molecule found. Guimarães at al. (2013), also described and quantified the phenolic composition of the herbal flowers, infusion and decoction preparation of wild $M$. recutita, reporting a luteolin $O$-acylhexoside as the main phenolic compound found.

There are available in the literature several reports on the antioxidant activity of chamomile essential oils (e.g., Gawde, Cantrell, Zheljazkov, Astatkie \& Schlegeld, 2014; Formisano, Delfine, Oliviero, Tenore, Rigano \& Senatore, 2015), however, studies with other kind of extracts are not so frequent. Among the antioxidant activity assays chamomile extract showed to be more active against TBARS, which $\mathrm{EC}_{50}$ values 
were close to those obtained with the standard trolox (Figure 2A). DPPH scavenging activity and reducing power of the decoction was similar to the ones previously described for methanolic extracts (Guimarães at al., 2013), while the lipid peroxidation inhibition, measured by $\beta$-carotene bleaching and TBARS inhibition assays, was higher in the present study. Roby et al. (2013) reported a higher DPPH scavenging activity of chamomile methanolic and ethanolic extracts in comparison with diethyl ether and hexane ones.

The antibacterial and antifungal activities of the chamomile extract were tested against a panel of eight bacteria and fungi strains, respectively, selected on the basis of their relevance to public health. The most susceptible bacteria were Staphylococcus aureus, Bacillus cereus and Salmonella typhimurium, while Penicillium funiculosum, Aspergillus versicolor (Figure 2B and $\mathbf{C}$ ) and Trichoderma viride were the most vulnerable fungi to the tested extract (Figure 2D and E). It should be highlighted that the chamomile extract showed higher activity (lower MIC values) than the standard ampicillin (Figure 2B) for five of the tested bacteria ( $S$. aureus, B. cereus, Pseudomonas aeruginosa, Escherichia coli and S. typhimurium), and than ketoconazole (Figure 2D) for three of the fungi (Aspergillus ochraceus, T. viride and Penicillium ochrochloron). Roby et al. (2013) had previously reported B. cereus and A. flavus as the most sensitive microorganisms to chamomile extracts. Nevertheless, according to Petronilho, Maraschin, Coimbra and Rocha (2012), aqueous extracts were effective against molds and yeasts, while ethanolic extracts showed the highest activity against bacteria. Cvetanović, Svarc-Gajić, Masković, Savić and Nikolić (2014) concluded that chamomile extracts have antimicrobial activity independently on the solvent (water and ethanol 70\%) and the extraction technique (Soxhlet, microwave-assisted, ultrasoundassisted and subcritical water extraction) used. 


\subsection{Incorporation of chamomile-based natural ingredients in cottage cheese}

Three groups of cottage cheese were prepared: the control (samples without any chamomile-based ingredient), the samples with the characterized chamomile phenolic extract obtained by decoction and also the samples incorporated with chamomile powder (this group was prepared in order to evaluate if the decoction process would be necessary or if it would be enough to incorporate the all plant instead of an extract). All the samples were evaluated for nutritional characteristics, colour and antioxidant activity.

\subsubsection{Effects on nutritional parameters}

In all the evaluated parameters, it was intended to verify the effects of functionalizing agent, independently of the number of days kept in storage, as well as the specific effect of the storage time, irrespectively of having plain cottage cheese or one the prepared functionalized products. Thereby, results were compared through a 2-way ANOVA, following the generalized linear model coupled to the repeated measures analysis technique. In this analysis, it is important to check for the homogeneity of variances in the measures done for each assayed condition. Since the independence of variables cannot be assumed, the former requirement was evaluated by the Mauchly's sphericity test.

The results for moisture, protein, fat, carbohydrates and energy in the prepared cottage cheeses are presented in Table 2. The evaluated factors, functionalizing agent (FA) and storage time $(\mathrm{ST})$ showed a significant interaction $(\mathrm{FA} \times \mathrm{ST})$ in all cases, which hinders the possibility of identifying unequivocal effects of each individual factor. Nevertheless, some specific trends were observed: protein, ash, fat and carbohydrates contents 
reached maximal values after 14 days of storage (and consequently the highest energy values), while moisture and lactose had exactly the opposite behavior. The same tendency was described by Farahani, Ezzatpanah and Abbasi (2014) for protein and fat contents during ripening of Siahmazgi cheese (typical Iranian cheese). Nevertheless, other authors have reported a decrease in protein values along shelf life of ripe cheese (Pappa, Kandarakis, Anifantakis, Zerfiridis, Anifantakis and Sotirakoglou, 2006), and "coalho" cheese (Queiroga et al., 2013). The decrease in lactose is in agreement with the results obtained by Diezhandino, Fernández, González, McSweeney and Fresno (2015) during the ripening of Valdeón cheese (Spanish blue cheese).

Regarding the effect of FA, control samples tended to present higher contents in ash, fat and also the highest energy values. On the other hand, samples functionalized with chamomile decoctions presented the maximal values in protein and carbohydrates, while those prepared with chamomile powder gave higher moisture contents.

The significant interaction among factor was also observed for all studied fatty acids (Table 2), which were also significantly changed by each individual factor $(p<0.05)$. In all samples, the predominant fatty acids, independently of being added with chamomile-based ingredients, were palmitic (C16:0) and oleic (C18:1acids (Table 2), which is also supported by studies with other kinds of cheese such as Portuguese “coalho" cheese (Queiroga et al., 2013) and French goat milk cheeses (AFSSA, 2010). The order of abundance in fatty acids was saturated fatty acids (SFA), followed by monounsaturated fatty acids (MUFA) and polyunsaturated fatty acids (PUFA).

After a careful observation of the obtained data, and despite the detected significant differences, the effects caused by either FA or ST were very low in magnitude, indicating that the fatty acids profile of cottage cheese is not severely affected by both factors. 


\subsubsection{Effects on colour and antioxidant parameters}

In the case of colour parameters, the interaction among factors was not significant for $L^{*}$ and $b^{*}$, allowing to identify the exact way how each of the parameters is affected by the assayed conditions. Lightness $\left(L^{*}\right)$ diminished along ST, being also lower in those samples prepared with chamomile powder. Similar $L^{*}$ values were described in studies with ricotta cheeses (Pizzillo, Claps, Cifuni, Fedele \& Rubino, 2005) and "coalho" cheeses (Queiroga et al., 2013). For $a^{*}$ parameter, which is a direct indicator of redness, no statistical significant difference was found along ST, while samples prepared with chamomile powder presented slightly higher values. A study with ricotta cheeses presented also redness values close to zero $\left(a^{*}=1.19-1.32\right)$ (Pizzillo et al., 2005). Other authors who studied the changes in colour characteristics during ripening of cheeses demonstrated that the $a^{*}$ value did not show a defined trend (Buffa et al., 2001). Regarding the blueness $\left(b^{*}\right)$ parameter, the highest values were obtained in samples functionalized with chamomile powder and those stored duting 14 days. On the other hand, the lowest values, i.e., the samples with less yellowness degree, were detected in plain cottage cheese and in non-stored samples. Ginzinger, Jaros, Lavanchy and Rohm (1999) confirmed that yellowness index increased with cheese aging. Previous research related with cheese colour as a function of ripening time reported a decrease in $L^{*}$ value and an increase in $b^{*}$ value (Rohm and Jaros,1996; Buffa, Trujillo, Pavia \& Guamis, 2001).

The appearance of the different cottage cheese samples after 14 days of storage is shown in Figure 3, where it can be observed that only the control sample showed signs of degradation.

The incorporation of chamomile-based ingredients improved the antioxidant activity 
(DPPH scavenging activity and reducing power) of plain cottage cheese samples (Table 3), without great differences among chamomile powder and decoction. Along the shelf life, DPPH scavenging activity showed a slight decrease, while reducing power showed a high increase, which might be related with the decrease in lactose (Table 2) and the consequent release of their reducing monomers. Another study conducted in our laboratory (Caleja et al., 2015) showed that the incorporation of a fennel (Foenniculum vulgare Mill.) phenolic-enriched extract, obtained by decoction, improved the antioxidant properties of cottage cheese, but the $\mathrm{EC}_{50}$ values reported demonstrate that the improvement antioxidant capacity of fennel was lower than the one showed by chamomile in the present work.

\section{Conclusions}

The characterization of $M$. recutita (chamomile) extracts obtained by decoction revealed the presence of phenolic compounds, which can be related with their antioxidant and antimicrobial activities. The incorporation of those extracts (chamomile based ingredients) to goat cottage cheese improved its antioxidant properties without significantly modifying the nutritional characteristics or fatty acids profiles. Moreover, only the control samples not added with the chamomile extracts presented signs of degradation after 14 days of storage. In view of the growing interest of consumers for functional foods without chemical additives and taking into account that the studied dairy product is highly appreciated, it would be interesting to go further in the development of this novel formulation in order to preserve the antioxidant activity along the shelf life of cottage cheese by using stabilization/microencapsulation techniques.

\section{Acknowledgements}

The authors are grateful to project PRODER $n^{\circ}$ 46577- PlantLact for financial support 
and to Foundation for Science and Technology (FCT, Portugal) for C. Caleja PhD grant (SFRH/BD/93007/2013), J.C.M. Barreira post-doctoral grant (SFRH/BPD/72802/2010)

and L. Barros research contract. The authors also thank Serbian Ministry of Education, Science and Technological Development for financial support (grant number 173032). The authors also thank to Ms Clarinda Paixão, from Américo Duarte Paixão Lda, for providing the plant samples.

\section{References}

AFSSA saisine no 2006-SA-0359 (1 ${ }^{\mathrm{er}}$ mars 2010). Avis de l'Agence franc, aise de sécurité sanitaire des aliments relatif à l'actualisation des apports nutritionnels conseillés pour les acides gras, 1-10.

Alanís, A., Calzada, F., Cervantes, J.A., Torres, J., \& Ceballos, G.M. (2005). Antibacterial properties of some plants used in Mexican traditional medicine for the treatment of gastrointestinal disorders. Journal of Ethnopharmacology, 100, $153-157$.

AOAC. (2005). Official methods of analysis of AOAC international. In W. Horwitz, \& G. Latimer (Eds.) (18th ed.). Gaithersburg, MD: AOAC International.

Assis, C., Gondim, M., Siqueira, H., \& Câmara, C. (2011). Toxicity of essential oils from plants towards Tyrophagus putrescentiae (Schrank) and Suidasia pontifica Oudemans (Acari: Astigmata). Journal of Stored Products Research, 47, 311-315.

Atoui, A.K., Mansouri, A., Boskou, G., \& Kefalas, P. (2005). Tea and herbal infusions: Their antioxidant activity and phenolic profile. Food Chemistry, 89, 27-36.

Avula, B., Wang, Y.-H., Wang, M., Avonto, C., Zhao, J., Smillie, T. J., Rua, D., \& Khan I. A. (2014). Quantitative determination of phenolic compounds by UHPLC-UV-MS and use of partial least-square discriminant analysis to 
differentiate chemo-types of Chamomile/Chrysanthemum flower heads. Journal of Pharmaceutical and Biomedical Analysis, 88, 278-288.

Barros, L., Pereira, E., Calhelha, R.C., Dueñas, M., Carvalho, A.M., Santos-Buelga, C., \& Ferreira, I.C.F.R. (2013). Bioactivity and chemical characterization in hydrophilic and lipophilic compounds of Chenopodium ambrosioides L. Journal of Functional Foods, 5, 1732-1740.

Buffa, M., Trujillo, A. J., Pavia, M., \& Guamis, B. (2001). Changes in textural, microstructural, and colour characteristics during ripening of cheeses made from raw, pasteurized or high-pressure-treatedgoats' milk. International Dairy Journal, $11,927-934$.

Bulgari, M., Sangiovanni, E., Colombo, E., Maschi, O., Caruso, D., Bosisio, E., \& Dell'Agli, M. (2012). Inhibition of neutrophil elastase and metalloprotease-9 of human adenocarcinoma gastric cells by chamomile (Matricaria recutita L.) infusion. Phytotherapy Research, 26, 1817-1822.

Caleja, C., Barros, L., Antonio, A.L., Ciric, A., Sokovic, M., Oliveira, M.B.P.P, SantosBuelga, C., \& Ferreira, I.C.F.R. (2015). Foeniculum vulgare Mill. as natural conservation enhancer and health promoter by incorporation in cottage cheese. Journal of Functional Foods, 12, 428-438.

Carocho, M., Barreiro, M., Morales, P., \& Ferreira, I.C.F.R. (2014). Adding Molecules to Food, Pros and Cons: A Review on Synthetic and Natural Food Additives. Comprehensive Reviews in Food Science and Food Safety, 13, 377-399.

Chandrashekhar, V.M., Halagali, K.S., Nidavani, R.B., Shalavadi, M.H., Biradar, B.S., Biswas, D., \& Muchchandi, I.S. (2011). Anti-allergic activity of German chamomile (Matricaria recutita L.) in mast cell mediated allergy model. Journal of Ethnopharmacology, 137, 336-340. 
Cvetanović, A., Svarc-Gajić, J., Masković, P., Savić, S., \& Nikolić, L. (2014). Antioxidant and biological activity of chamomile extracts obtained by different techniques: perspective of using superheated water for isolation of biologically active compounds. Industrial Crops and Products, doi:10.1016/j.indcrop.2014.09.044.

Díaz-Castro, J., Pérez-Sánchez, L.J., López-Frías, M.R., López-Aliaga, I., Nestares, T., Alférez, M.J., Ojeda, M.L., \& Campos, M.S. (2012). Influence of cow or goat milk consumption on antioxidant defence and lipid peroxidation during chronic iron repletion. British Journal of Nutrition, 108, 1-8.

Diezhandino, I., Fernández, D., González, L., McSweeney,P.L.H., \& Fresno, J.M. (2015). Microbiological, physico-chemical and proteolytic changes in a Spanish blue cheese during ripening (Valdeón cheese). Food Chemistry, 168, 134-141.

Farahani, G., Ezzatpanah, H., \& Abbasi, S. (2014). Characterization of Siahmazgi cheese, an Iranian ewe's milk variety: Assessment of physico-chemical, textural and rheological specifications during ripening. LWT - Food Science and Technology, 58, 335-342.

Fernandes, Â., Antonio, A.L., Barreira, J.C.M., Oliveira, M.B.P.P., Martins, A., \& Ferreira, I.C.F.R. (2012). Effects of gamma irradiation on physical parameters of Lactarius deliciosus wild edible mushrooms. Postharvest Biology and Technology, 74, 79-84.

Formisano, C., Delfine S., Oliviero, F., Tenore, G. C., Rigano, D., \& Senatore F. (2015). Correlation among environmental factors, chemical composition and antioxidative properties of essential oil and extracts of chamomile (Matricaria chamomilla L.) collected in Molise (South-central Italy). Industrial Crops and Products, 63, 256-263. 
Gawde, A., Cantrell, C.L., Zheljazkov, V.D., Astatkie, T., \& Schlegeld, V. (2014). Steam distillation extraction kinetics regression models to predictessential oil yield, composition, and bioactivity of chamomile oil. Industrial Crops and Products, 58, 61-67.

Ginzinger, W., Jaros, D., Lavanchy, P., \& Rohm, H. (1999). Raw milk flora affects composition and quality of Bergkäse-3. Physical and sensory properties, and conclusions. Le Lait- Dairy Science and Technology, 79, 411-421.

Guimarães, R., Barros, L., Dueñas, M., Calhelha, R.C., Carvalho, A.M, Santos-Buelga, C., Queiroz, M.J.R.P., \& Ferreira, I.C.F.R. (2013). Infusion and decoction of wild German chamomile: Bioactivity and characterization of organic acids and phenolic compounds. Food Chemistry, 136, 947-954.

Haenlein, G.F.W. (2004). Goat milk in human nutrition. Small Ruminant Research, 51, $155-163$.

Haghi, G., Hatami, A., Safaei, A., \& Mehran, M. (2014). Analysis of phenolic compounds in Matricaria chamomilla and its extracts by UPLC-UV. Research in Pharmaceutical Sciences, 9, 31-37.

Kunde, R., \& Isaac, O. (1979). Über die Flavone der Kamille (Matricaria chamomilla L.) und ein neues acetyliertes Apigenin-7-glucosid. Planta Medica, 37, 124-130. Liao, S.-G., Zhang, L.-J., Li, C.-B., Lan, Y.-Y., Wang, A.-M., Huang, Y., Zhen, L., Fu, X.-Z., Zhou, W., Qi, X.-L., Guan Z.-Z., \& Wang Y.-L. (2010). Rapid screening and identification of caffeic acid and its esters in Erigeron breviscapus by ultraperformance liquid chromatography/tandem mass spectrometry. Rapid Communications in Mass Spectrometry, 24, 2533-2541. 
Lin, L.-Z., \& Harnly, J.M. (2012). LC-PDA-ESI/MS Identification of the Phenolic Components of Three Compositae Spices: Chamomile, Tarragon, and Mexican Arnica. Natural Products Communication, 7, 749-752.

Matić, I.Z., Juranić, Z., Savikin, K., Zdunić, G., Nadvinski, N., \& Godevac, D. (2013). Chamomile and marigold tea: chemical characterization and evaluation of anticancer activity. Phytotherapy Research, 27, 852-858.

Mulinacci, N., Romani, A., Pinelli, P., Vincieri, F.F., \& Prucher, D. (2000). Characterization of Matricaria recutita L. flower extracts by HPLC-MS and HPLC-DAD analysis. Chromatographia, 51, 301-307.

Nováková, L., Vildová, A., Mateus, J.P., Gonçalves, T., \& Solich, P. (2010). Development and application of UHPLC-MS/MS method for the determination of phenolic compounds in chamomile flowers and chamomile tea extracts. Talanta, $82,1271-1280$

Pappa, E., Kandarakis, I., Anifantakis, E., Zerfiridis, G., Anifantakis, A., \& Sotirakoglou, K. (2006). Influence of starter cultures on the proteolysis of Teleme cheese made from different types of milk. Le Lait-Dairy Science and Technology, $86,273-290$.

Petronilho, S., Maraschin, M., Coimbra, M.A., \& Rochaa, S.M. (2012). In vitro and in vivo studies of natural products: A challenge for their valuation. The case study of chamomile (Matricaria recutita L.). Industrial Crops and Products, 40, 1-12.

Pietta, P., Manera, E., \& Ceva P. (1987). Simultaneous isocratic high-performance liquid chromatographic determination of flavones and coumarins in Matricaria chamomilla extracts. Journal of Chromatography, 404, 279-281.

Pizzillo, M., Claps, S., Cifuni, G., Fedele, V., \& Rubino, R. (2005). Effect of goat breed on the sensory, chemical and nutritional characteristics of ricotta cheese. Livestock 
Production Science, 94, 33-40.

Procházková, D., Bousová, I., \& Wilhelmová, N. (2011). Antioxidant and prooxidant properties of flavonoids. Fitoterapia, 82, 513-523.

Queiroga, R., Santos, B., Gomes, A., Monteiro, M., Teixeira, S., Souza, E., Pereira, C., \& Pintado, M. (2013). Nutritional, textural and sensory properties of Coalho cheese made of goats', cows' milk and their mixture. LWT - Food Science and Technology, 50, 538-544.

Raal, A., Orav, A., Püssa, T., Valner, C., Malmiste, B., \& Arak, E. (2012). Content of essential oil, terpenoids and polyphenols in commercial chamomile (Chamomilla recutita L. Rauschert) teas from different countries. Food Chemistry, 131, 632638.

Randhawa, S., \& Bahna, S. (2009). Hypersensitivity reactions to food additives. Current Opinion in Allergy and Clinical Immunology, 9, 278-283.

Ranpariya, V.L., Parmar, S.K., Sheth, N.R., \& Chandrashekhar, V.M. (2011). Neuroprotective activity of Matricaria recutita against fluoride-induced stress in rats. Pharmaceutical Biology, 49, 696-701.

Rasooli, I. (2007). Food preservation - A biopreservative approach. Food, 1, 111-136.

Roby, M., Sarhan, M., Selim, K., \& Khalel, K. (2013). Antioxidant and antimicrobial activities of essential oil and extracts of fennel (Foeniculum vulgare L.) and chamomile (Matricaria chamomilla L.). Industrial Crops and Products, 44, 437445.

Rohm, H., \& Jaros, D. (1996). Colour of hardcheese-1. Description of colour properties and effects of maduration. Zeitschrift fur Lebensmittel Untersuchung Forschung, 203, 241-244.

Sarig, Y., De Baerdemaker, J., Marchal, P., Auernhammer, H., Bodria, L., de Alencar 
Nääs, I., Centrangolo, H. (2003). Traceability of food products. International Commission of Agricultural Engineering, 5, 1-17.

Silva, N. C., Barbosa, L., Seito, L. N., \& Fernandes, A. (2012). Antimicrobial activity and phytochemical analysis of crude extracts and essential oils from medicinal plants. Natural Product Research, 26, 1510-1514.

Soković, M., \& van Griensven, L.J.L.D. (2006). Antimicrobial activity of essential oils and their components against the three major pathogens of the cultivated button mushroom, Agaricus bisporus. European Journal of Plant Pathology, 116, 211224.

Soković, M., Glamočlija, J., Marin, M.D., Brkić, D., \& van Griensven, L.J.L.D. (2010). Antibacterial Effects of the Essential Oils of Commonly Consumed Medicinal Herbs Using an In Vitro Model. Molecules, 15, 7532-7546.

Svehlíková, V., Bennett, R.N., Mellon, F.A., Needs, P.W. Piacente, S., Kroon, P.A., \& Bao, Y. (2004). Isolation, identification and stability of acylated derivatives of apigenin 7-O-glucoside from chamomile (Chamomilla recutita [L.] Rauschert). Phytochemistry, 65, 2323-2332.

Weber, B., Herrmann, M., Hartmann, B., Joppe, H., Schmidt C.O., \& Heinz-Jürgen, B. (2008). HPLC/MS and HPLC/NMR as hyphenated techniques for accelerated characterization of the main constituents in Chamomile (Chamomilla recutita [L.] Rauschert). European Food Research and Technology, 226, 755-760.

Weng, C., \& Yen G. (2012). Chemopreventive effects of dietary phytochemicals against cancer invasion and metastasis: Phenolic acids, monophenol, polyphenol, and their derivatives. Cancer Treatment Reviews, 38, 76-87.

Xie, X.-Y., Wang, R., \& Shi, Y.-P. (2014). Flavonoids from the flowers of Matricaria chamomilla. Chemistry of Natural Compounds, 50, 910-311. 
Zapata, N., \& Smagghe, G. (2010). Repellency and toxicity of essential oils from the leaves and bark of Laurelia sempervirens and Drimys winteri against Tribolium castaneum. Industrial Crops and Products, 32, 405-410.

Zhang, Y., Shi, P., Qu, H., \& Cheng, Y. (2007). Characterization of phenolic compounds in Erigeron breviscapus by liquid chromatography coupled to electrospray ionization mass spectrometry. Rapid Communications in Mass Spectrometry, 21, 2971-2984.

Zhang, Y., Zhao, Q., Ma, J., Wu, B., \& Zeng, X. (2010). Chemical characterization of phenolic compounds in Erigeron injection by rapid-resolution LC coupled with multi-stage and quadrupole-TOF-MS. Journal of Chromatography, 72, 651-658.

Zhao, J., Khan, S.I., Wang, M., Vasquez, Y., Yang, M.H., Avula, B., Wang, Y-H, Avonto, C., Smillie, T.J., \& Khan, I.A. (2014). Octulosonic Acid Derivatives from Roman Chamomile (Chamaemelum nobile) with Activities against Inflammation and Metabolic Disorder. Journal of Natural Products, 77, 509515.

Zielinski, A.A.F., Haminiuk, C.W.I., Alberti, A., Nogueira, A., Demiate I.M., \& Granato, D. (2014). A comparative study of the phenolic compounds and the in vitro antioxidant activity of different Brazilian teas using multivariate statistical techniques. Food Research International, 60, 246-254. 
Table 1. Retention time (Rt), wavelengths of maximum absorption in the visible region $\left(\lambda_{\max }\right)$, mass spectral data, identification and quantification of phenolic compounds in chamomile decoction. The results are presented as mean \pm standard deviation $(\mathrm{n}=9)$.

\begin{tabular}{|c|c|c|c|c|c|c|}
\hline Compound & Rt (min) & $\begin{array}{c}\lambda_{\max } \\
(\mathrm{nm})\end{array}$ & $\begin{array}{l}\text { Pseudomolecul } \\
\text { ar ion } \\
{[\mathrm{M}-\mathrm{H}]^{-}(\mathrm{m} / \mathrm{z})}\end{array}$ & $\begin{array}{l}\mathrm{MS}^{2} \\
(\mathrm{~m} / z)\end{array}$ & Tentative identification & $\begin{array}{l}\text { Quantification } \\
(\mathrm{mg} / \mathrm{g})\end{array}$ \\
\hline 1 & 5.6 & 320 & 341 & $179(100)$ & Caffeic acid hexoside & $0.25 \pm 0.04$ \\
\hline 2 & 6.1 & $256 / 296$ & 153 & $109(100)$ & Protocatechuic acid & $0.42 \pm 0.04$ \\
\hline 3 & 7.8 & 328 & 353 & 191(100),179(15),161(18),135(10) & 5-O-caffeoylquinic acid & $5.87 \pm 0.03$ \\
\hline 4 & 8.5 & 328 & 381 & $293(5), 251(8), 219(18), 203(11), 179(70), 161(100), 135(44)$ & $3-\mathrm{CDOA}$ & $1.62 \pm 0.06$ \\
\hline 5 & 11.1 & 324 & 179 & $135(100)$ & Caffeic acid & $1.45 \pm 0.03$ \\
\hline 6 & 16.1 & 358 & 479 & $317(100)$ & Myricetin-3-O-glucoside & $4.57 \pm 0.13$ \\
\hline 7 & 17.8 & 358 & 639 & $315(10), 300(45)$ & Isorhmanetin- $O$-dihexoside & $0.74 \pm 0.09$ \\
\hline 8 & 19.2 & 358 & 463 & $301(100)$ & Quercetin-3-O-glucoside & $0.70 \pm 0.06$ \\
\hline 9 & 19.8 & 348 & 447 & $285(100)$ & Luteolin-7-O-glucoside & $1.89 \pm 0.18$ \\
\hline 10 & 20.2 & 348 & 461 & $285(100)$ & Luteolin- $O$-glucuronide & $4.80 \pm 0.54$ \\
\hline 11 & 21.9 & 328 & 515 & $353(100), 191(73), 179(64), 161(4), 135(23)$ & cis 3,5-O-Dicaffeoylquinic acid & $1.71 \pm 0.02$ \\
\hline 12 & 22.1 & 328 & 515 & $353(100), 191(82), 179(69), 161(6), 135(25)$ & trans 3,5-O-Dicaffeoylquinic acid & $1.30 \pm 0.06$ \\
\hline 13 & 22.6 & 328 & 543 & $381(62), 363(21), 319(10), 251(6), 221(24), 203(16), 179(83), 161(82), 135(42)$ & Erigoster B (3,9-diCDOA) & $1.21 \pm 0.02$ \\
\hline 14 & 23.0 & 328 & 543 & $381(65), 363(18), 319(7), 251(3), 221(18), 203(7), 179(59), 161(50), 135(25)$ & 4,9-diCDOA (or 3,4 diCDOA) & $6.83 \pm 0.05$ \\
\hline 15 & 24.6 & 336 & 431 & $269(100)$ & Apigenin-7-O-glucoside & $3.24 \pm 0.11$ \\
\hline 16 & 27.2 & 356 & 519 & $315(100), 300(30)$ & Isorhmanetin- $O$-acetylhexoside & $0.14 \pm 0.04$ \\
\hline 17 & 29.5 & 334 & 473 & $269(100)$ & Apigenin-7-O-acetylglucoside & $1.08 \pm 0.13$ \\
\hline 18 & 30.1 & 338 & 269 & $225(5), 151(3), 149(3), 117(10)$ & Apigenin & $0.73 \pm 0.02$ \\
\hline \multirow[t]{4}{*}{19} & 32.8 & 328 & 705 & $543(32), 381(11), 319(4), 259(4), 221(5), 179(23), 161(7), 135(7)$ & 3,4,9-triCDOA & $3.00 \pm 0.36$ \\
\hline & & & & & Total phenolic acids & $23.66 \pm 0.27$ \\
\hline & & & & & Total flavonoids & $17.89 \pm 0.91$ \\
\hline & & & & & Total phenolic compounds & $41.54 \pm 1.18$ \\
\hline
\end{tabular}

CDOA-caffeoyl-2,7-anhydro-3-deoxy-2-octulopyranosonic acids. 
Table 2. Nutritional value (g/100 g), energy ( $\mathrm{kcal} / 100 \mathrm{~g})$ and fatty acids composition (relative percentage) of the cottage cheese samples along shelf life. Results are presented

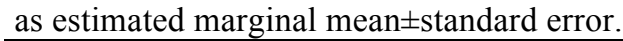

\begin{tabular}{|c|c|c|c|c|c|c|c|c|c|c|c|c|}
\hline \multirow{2}{*}{ Storage days } & \multicolumn{3}{|c|}{ Functionalizing agent (FA) } & \multirow{2}{*}{$\begin{array}{c}\text { Mauchly's test } \\
\text { of sphericity } \\
\text { (p-value) }\end{array}$} & \multirow[b]{2}{*}{$p$-value ${ }^{\mathrm{a}}$} & \multicolumn{3}{|c|}{ Storage time (ST) } & \multirow{2}{*}{$\begin{array}{c}\text { Mauchly's test of } \\
\text { sphericity } \\
\text { (p-value) }\end{array}$} & \multirow[b]{2}{*}{$p$-value ${ }^{\mathrm{a}}$} & \multicolumn{2}{|c|}{ FA $\times$ ST interaction } \\
\hline & Control & $\begin{array}{l}\text { Chamomile } \\
\text { powder }\end{array}$ & $\begin{array}{l}\text { Chamomile } \\
\text { decoction }\end{array}$ & & & 0 days & 7 days & 14 days & & & $\begin{array}{c}\text { Mauchly's test } \\
\text { (p-value) }\end{array}$ & $p$-value \\
\hline \multicolumn{13}{|c|}{ Nutritional value } \\
\hline Moisture & $62.5 \pm 0.2$ & $64.0 \pm 0.2$ & $62.3 \pm 0.2$ & $0.965(0.881)$ & $<0.001$ & $64.5 \pm 0.1$ & $64.5 \pm 0.2$ & $59.9 \pm 0.2$ & $0.618(0.185)$ & $<0.001$ & $0.617(0.962)$ & $<0.001$ \\
\hline Protein & $12.1 \pm 0.1$ & $12.3 \pm 0.1$ & $12.7 \pm 0.1$ & $0.873(0.621)$ & $<0.001$ & $11.6 \pm 0.1$ & $12.2 \pm 0.1$ & $13.3 \pm 0.1$ & $0.429(0.052)$ & $<0.001$ & $0.114(0.137)$ & $<0.001$ \\
\hline Ash & $2.26 \pm 0.04$ & $2.09 \pm 0.05$ & $2.24 \pm 0.05$ & $0.498(0.087)$ & 0.005 & $2.23 \pm 0.05$ & $2.05 \pm 0.05$ & $2.32 \pm 0.04$ & $0.538(0.114)$ & $<0.001$ & $0.147(0.211)$ & $<0.001$ \\
\hline Fat & $20.4 \pm 0.4$ & $19.3 \pm 0.2$ & $19.3 \pm 0.2$ & $0.656(0.229)$ & $<0.001$ & $19.0 \pm 0.3$ & $18.9 \pm 0.2$ & $21.2 \pm 0.1$ & $0.650(0.222)$ & $<0.001$ & $0.016(0.002)$ & $<0.001$ \\
\hline Carbohydrates & $2.6 \pm 0.2$ & $2.3 \pm 0.2$ & $3.7 \pm 0.3$ & $0.545(0.119)$ & $<0.001$ & $2.7 \pm 0.2$ & $2.5 \pm 0.3$ & $3.3 \pm 0.3$ & $0.894(0.676)$ & 0.002 & $0.026(0.027)$ & $<0.001$ \\
\hline Lactose & $1.91 \pm 0.04$ & $1.72 \pm 0.04$ & $2.03 \pm 0.04$ & $0.270(0.010)$ & $<0.001$ & $2.05 \pm 0.03$ & $2.05 \pm 0.04$ & $1.56 \pm 0.03$ & $0.884(0.651)$ & $<0.001$ & $0.362(0.697)$ & $<0.001$ \\
\hline Energy & $243 \pm 2$ & $232 \pm 1$ & $239 \pm 1$ & $0.819(0.497)$ & $<0.001$ & $228 \pm 2$ & $228 \pm 2$ & $257 \pm 2$ & $0.877(0.631)$ & $<0.001$ & $0.187(0.309)$ & $<0.001$ \\
\hline \multicolumn{13}{|l|}{ Fatty acids } \\
\hline $\mathrm{C} 4: 0$ & $7.3 \pm 0.1$ & $6.4 \pm 0.1$ & $6.4 \pm 0.1$ & $0.426(0.051)$ & $<0.001$ & $7.3 \pm 0.1$ & $6.3 \pm 0.1$ & $6.5 \pm 0.1$ & $0.629(0.198)$ & $<0.001$ & $0.019(0.003)$ & $<0.001$ \\
\hline C6:0 & $6.6 \pm 0.1$ & $5.3 \pm 0.1$ & $5.3 \pm 0.1$ & $0.416(0.047)$ & $<0.001$ & $5.9 \pm 0.1$ & $5.5 \pm 0.1$ & $5.8 \pm 0.1$ & $0.410(0.044)$ & 0.001 & $0.006(<0.001)$ & $<0.001$ \\
\hline $\mathrm{C} 8: 0$ & $4.7 \pm 0.1$ & $4.3 \pm 0.1$ & $4.3 \pm 0.1$ & $0.642(0.212)$ & $<0.001$ & $4.4 \pm 0.1$ & $4.3 \pm 0.1$ & $4.6 \pm 0.1$ & $0.432(0.053)$ & $<0.001$ & $0.015(0.002)$ & $<0.001$ \\
\hline C10:0 & $10.1 \pm 0.1$ & $10.9 \pm 0.1$ & $10.8 \pm 0.1$ & $0.785(0.428)$ & $<0.001$ & $10.5 \pm 0.1$ & $10.1 \pm 0.1$ & $11.1 \pm 0.1$ & $0.442(0.058)$ & $<0.001$ & $0.042(0.019)$ & $<0.001$ \\
\hline $\mathrm{C} 12: 0$ & $4.7 \pm 0.1$ & $5.4 \pm 0.1$ & $5.4 \pm 0.1$ & $0.551(0.124)$ & $<0.001$ & $5.1 \pm 0.1$ & $4.9 \pm 0.1$ & $5.4 \pm 0.1$ & $0.625(0.193)$ & $<0.001$ & $0.011(0.001)$ & 0.001 \\
\hline $\mathrm{C} 14: 0$ & $9.1 \pm 0.1$ & $10.7 \pm 0.1$ & $10.6 \pm 0.1$ & $0.486(0.080)$ & $<0.001$ & $10.1 \pm 0.1$ & $9.8 \pm 0.1$ & $10.4 \pm 0.1$ & $0.729(0.331)$ & $<0.001$ & $0.026(0.007)$ & $<0.001$ \\
\hline C15:0 & $1.08 \pm 0.02$ & $1.27 \pm 0.02$ & $1.25 \pm 0.01$ & $0.239(0.007)$ & $<0.001$ & $1.18 \pm 0.04$ & $1.19 \pm 0.01$ & $1.21 \pm 0.01$ & $0.544(0.118)$ & $<0.001$ & $0.003(<0.001)$ & $<0.001$ \\
\hline C16:0 & $20.6 \pm 0.3$ & $21.9 \pm 0.5$ & $21.9 \pm 0.3$ & $0.960(0.868)$ & $<0.001$ & $21.5 \pm 0.1$ & $21.6 \pm 0.2$ & $21.2 \pm 0.2$ & $0.894(0.677)$ & $<0.001$ & $0.013(0.001)$ & $<0.001$ \\
\hline C18:0 & $10.2 \pm 0.2$ & $9.3 \pm 0.1$ & $9.1 \pm 0.1$ & $0.789(0.437)$ & $<0.001$ & $9.6 \pm 0.1$ & $9.9 \pm 0.1$ & $9.1 \pm 0.2$ & $0.810(0.479)$ & $<0.001$ & $0.002(<0.001)$ & 0.001 \\
\hline C18:1 & $18.7 \pm 0.2$ & $18.1 \pm 0.1$ & $18.5 \pm 0.1$ & $0.306(0.016)$ & $<0.001$ & $18.0 \pm 0.1$ & $19.3 \pm 0.2$ & $18.1 \pm 0.1$ & $0.589(0.157)$ & $<0.001$ & $0.006(<0.001)$ & $<0.001$ \\
\hline C18:2 & $2.8 \pm 0.1$ & $2.5 \pm 0.1$ & $2.5 \pm 0.1$ & $0.698(0.284)$ & $<0.001$ & $2.6 \pm 0.1$ & $2.7 \pm 0.1$ & $2.5 \pm 0.1$ & $0.698(0.284)$ & $<0.001$ & $0.061(0.041)$ & 0.035 \\
\hline $\mathrm{C} 18: 3$ & $1.58 \pm 0.01$ & $1.53 \pm 0.01$ & $1.51 \pm 0.01$ & $0.178(0.002)$ & $<0.001$ & $1.54 \pm 0.01$ & $1.59 \pm 0.01$ & $1.48 \pm 0.02$ & $0.452(0.062)$ & $<0.001$ & $0.009(0.001)$ & 0.003 \\
\hline SFA & $75.8 \pm 0.4$ & $76.8 \pm 0.5$ & $76.1 \pm 0.3$ & $0.828(0.516)$ & $<0.001$ & $76.9 \pm 0.4$ & $75.0 \pm 0.2$ & $76.9 \pm 0.5$ & $0.536(0.113)$ & $<0.001$ & $0.004(<0.001)$ & $<0.001$ \\
\hline MUFA & $19.3 \pm 0.1$ & $19.0 \pm 0.1$ & $19.5 \pm 0.1$ & $0.347(0.025)$ & 0.001 & $18.8 \pm 0.2$ & $20.2 \pm 0.1$ & $18.8 \pm 0.3$ & $0.267(0.010)$ & $<0.001$ & $0.016(0.002)$ & $<0.001$ \\
\hline PUFA & $4.8 \pm 0.1$ & $4.5 \pm 0.1$ & $4.4 \pm 0.1$ & $0.284(0.012)$ & $<0.001$ & $4.5 \pm 0.1$ & $4.7 \pm 0.1$ & $4.4 \pm 0.1$ & $0.524(0.104)$ & $<0.001$ & $0.021(0.004)$ & 0.001 \\
\hline
\end{tabular}


${ }^{a}$ Significance value for the tests of between subjects effects. When sphericity assumption was not met $(p<0.05)$, the $p$-value was obtained from the Greenhouse-Geisser correction.

Butiric acid (C4:0); Caproic acid (C6:0); Caprylic acid (C8:0); Capric acid (C10:0); Lauric acid (C12:0); Myristic acid (C14:0); Pentadecanoic acid (C15:0); Palmitic acid (C16:0); Stearic acid (C18:0); Oleic acid (C18:1); Linoleic acid (C18:2); $\alpha$-Linolenic acid (C18:3); SFA- Saturated fatty acids; MUFA- Monounsaturated fatty acids; PUFAPolyunsaturated fatty acids. The difference to $100 \%$ corresponds to other 17 less abundant fatty acids (data not shown). The results of control cottage cheese samples were previously published by the authors (Caleja et al., 2015). 
Table 3. Colour parameters, free radicals scavenging activity and reducing power of the cottage cheese samples along shelf life. Results are presented as estimated marginal mean \pm standard error.

\begin{tabular}{|c|c|c|c|c|c|c|}
\hline & & \multicolumn{3}{|c|}{ Colour parameters } & \multicolumn{2}{|c|}{ Antioxidant activity $\left(\mathrm{EC}_{50}\right.$ values, $\left.\mathrm{mg} / \mathrm{mL}\right)$} \\
\hline & & $L^{*}$ & $a^{*}$ & $b^{*}$ & DPPH scavenging activity & Reducing power \\
\hline \multirow{3}{*}{ Functionalizing agent } & Control & $90 \pm 1$ & $-2.5 \pm 0.1$ & $12.2 \pm 0.2$ & $200^{b}$ & $85 \pm 1$ \\
\hline & Chamomile powder & $80 \pm 1$ & $-1.8 \pm 0.1$ & $18.6 \pm 0.4$ & $41 \pm 1$ & $5.9 \pm 0.1$ \\
\hline & Chamomile decoction & $88.6 \pm 0.3$ & $-2.3 \pm 0.1$ & $16.3 \pm 0.3$ & $44 \pm 1$ & $6.9 \pm 0.2$ \\
\hline \multicolumn{2}{|c|}{ Mauchly's test of sphericity ( $p$-value) } & $0.443(0.017)$ & $0.490(0.028)$ & $0.685(0.151)$ & $0.271(0.010)$ & $0.140(0.001)$ \\
\hline \multicolumn{2}{|l|}{$p$-value ${ }^{\mathrm{a}}$} & $<0.001$ & $<0.001$ & $<0.001$ & $<0.001$ & $<0.001$ \\
\hline \multirow{3}{*}{ Storage time (ST) } & 0 days & $88 \pm 1$ & $-2.2 \pm 0.1$ & $13.8 \pm 0.3$ & $90 \pm 1$ & $72 \pm 1$ \\
\hline & 7 days & $87 \pm 1$ & $-2.1 \pm 0.1$ & $14.8 \pm 0.2$ & $96 \pm 1$ & $17.6 \pm 0.1$ \\
\hline & 14 days & $83 \pm 1$ & $-2.2 \pm 0.1$ & $18.6 \pm 0.3$ & $99 \pm 1$ & $8.5 \pm 0.1$ \\
\hline \multicolumn{2}{|c|}{ Mauchly's test of sphericity ( $p$-value) } & $0.715(0.186)$ & $0.682(0.148)$ & $0.854(0.455)$ & $0.350(0.025)$ & $0.101(<0.001)$ \\
\hline \multicolumn{2}{|l|}{$p$-value ${ }^{\mathrm{a}}$} & $<0.001$ & 0.439 & $<0.001$ & $<0.001$ & $<0.001$ \\
\hline \multicolumn{7}{|l|}{ FA $\times$ ST interaction } \\
\hline \multicolumn{2}{|c|}{ Mauchly's test of sphericity ( $p$-value) } & $0.050(0.001)$ & $0.097(0.010)$ & $0.105(0.013)$ & $<0.001(<0.001)$ & $0.001(<0.001)$ \\
\hline \multicolumn{2}{|l|}{$p$-value ${ }^{\mathrm{a}}$} & 0.318 & 0.023 & 0.130 & 0.001 & $<0.001$ \\
\hline
\end{tabular}

${ }^{a}$ Significance value for the tests of between subjects effects. When sphericity assumption was not met $(p<0.05)$, the $p$-value was obtained from the Greenhouse-Geisser correction. ${ }^{\mathrm{b}}$ The presented value corresponds to the maximum assayed concentration, since it was not possible to reach $50 \%$ of activity up to that concentration. The results of control cottage cheese samples were previously published by the authors (Caleja et al., 2015). 


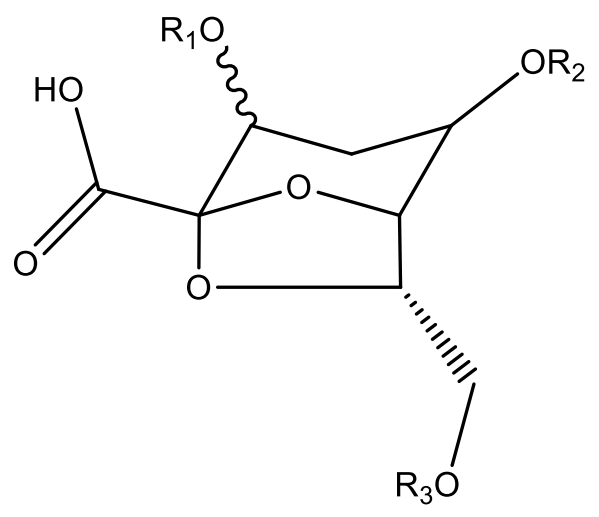

Figure 1. Structure of 2,7-anhydro-3-deoxy-2-octulopyranosonic acids; locations for the caffeoyl moieties. 


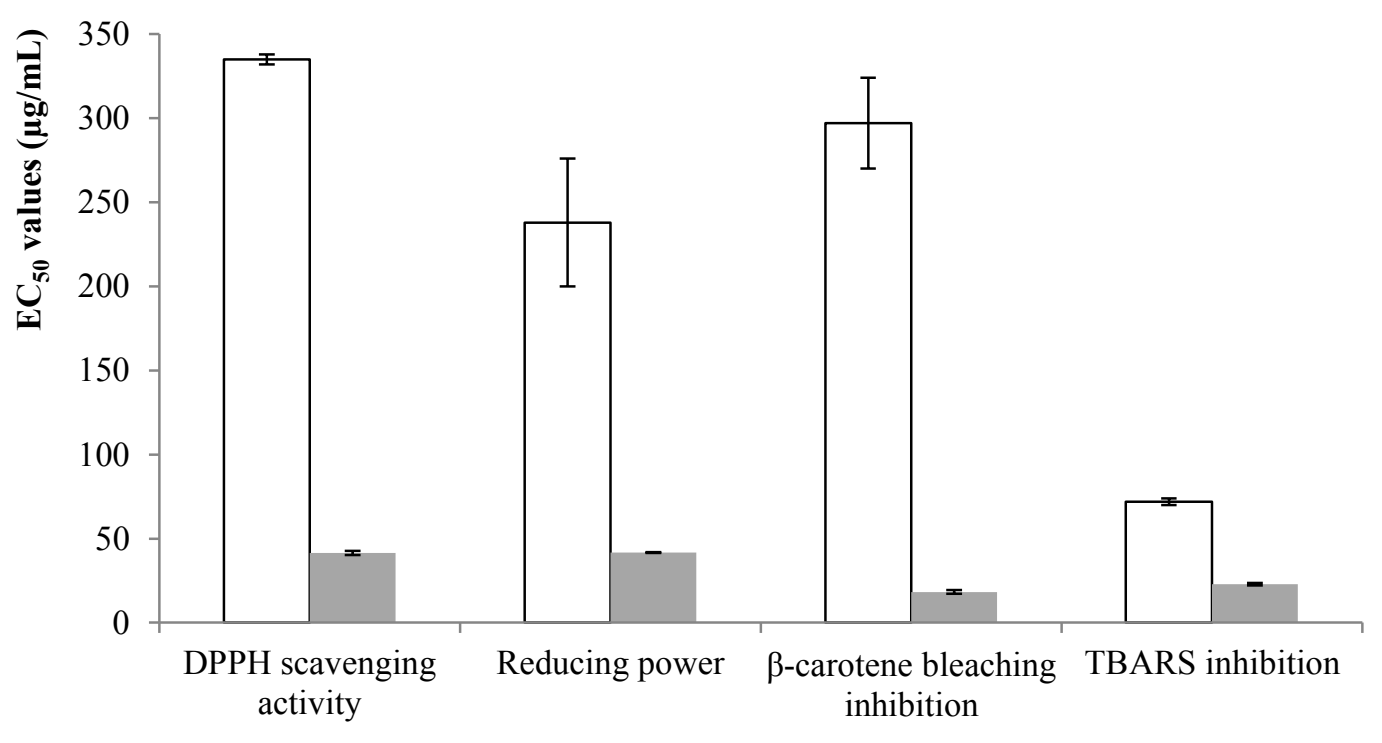

A

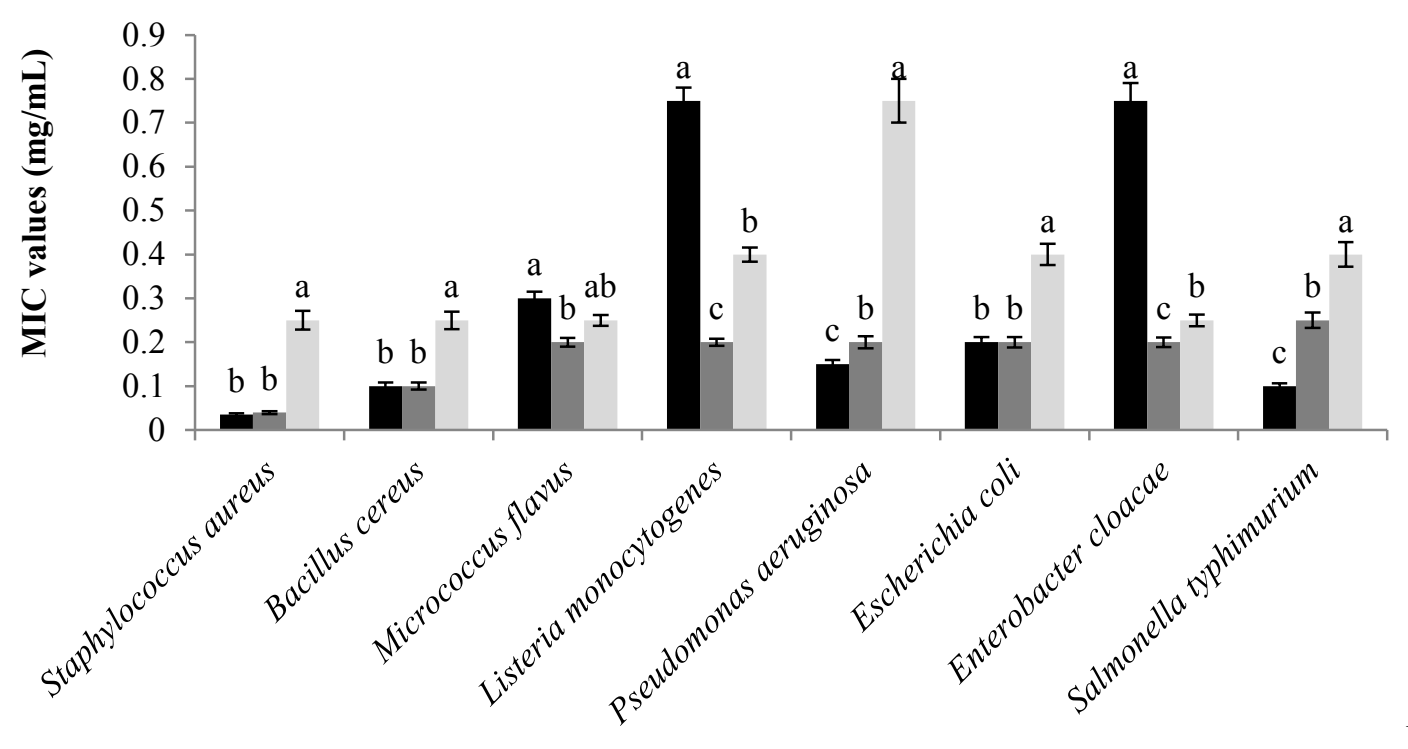

B

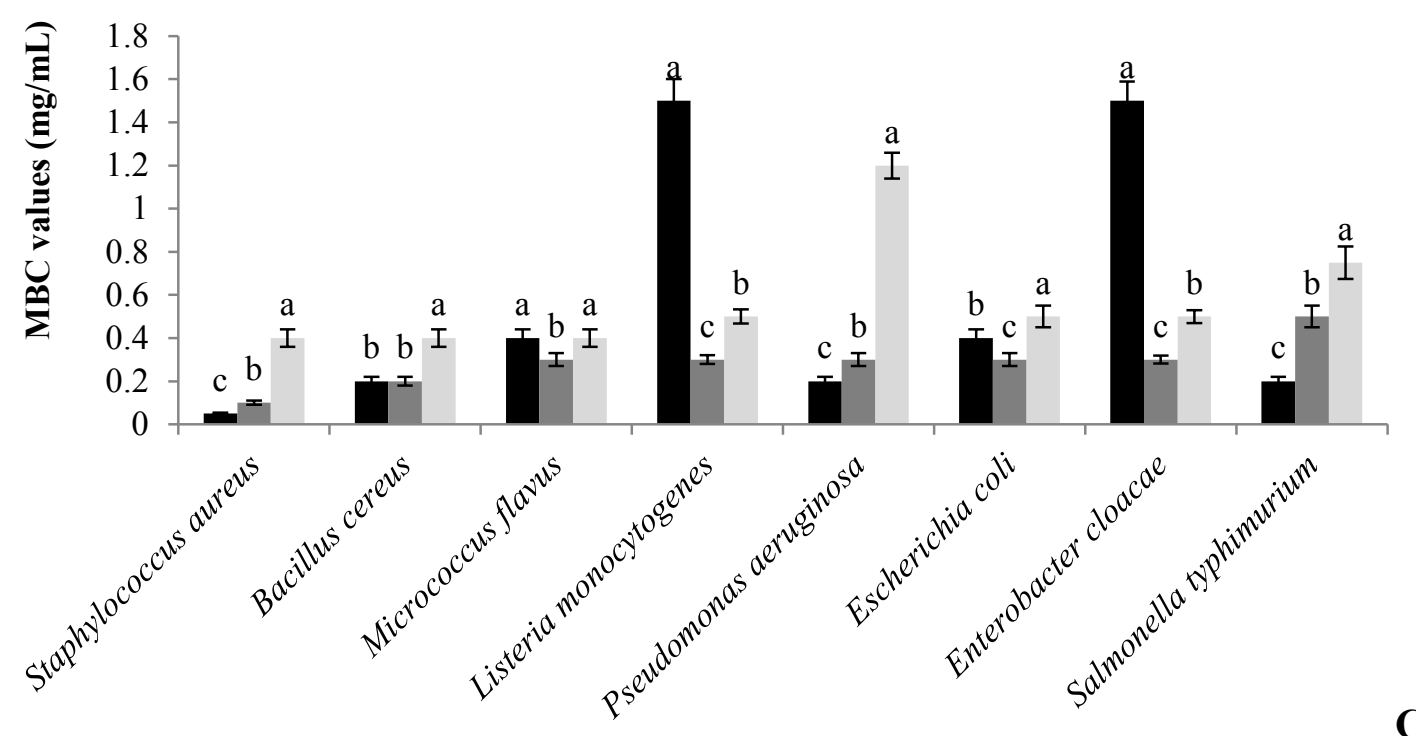



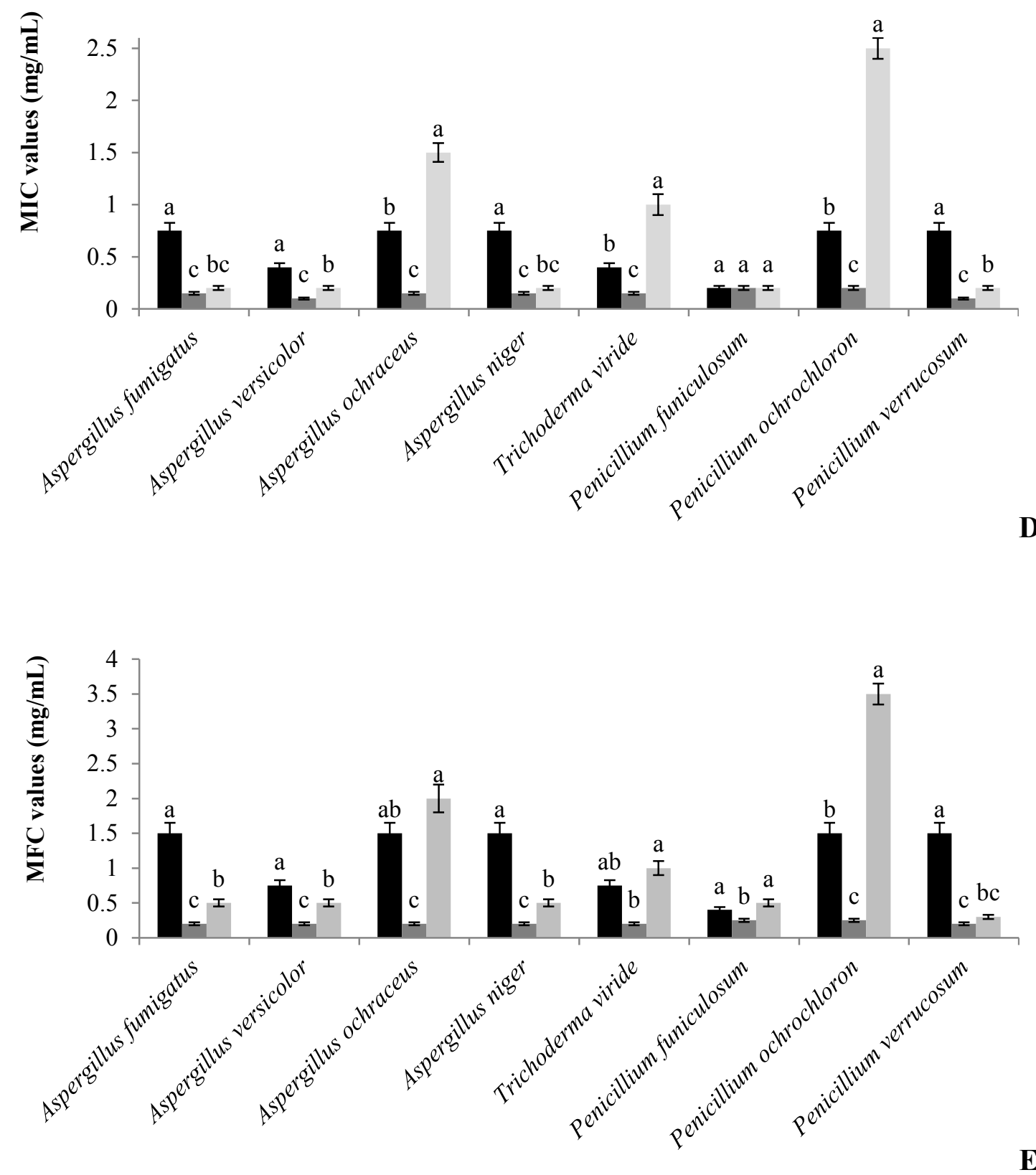

Figure 2. (A) Antioxidant activity of chamomile phenolic compounds extract obtained by decoction $(\square)$ and of the standard trolox $(\square)$. The antioxidant activity was expressed as $\mathrm{EC}_{50}$ values $(\mu \mathrm{g} / \mathrm{mL})($ Mean $\pm \mathrm{SD}, \mathrm{n}=9)$, what means that higher values correspond to lower reducing power or antioxidant potential. $\mathrm{EC}_{50}$ : Extract concentration corresponding to $50 \%$ of antioxidant activity or 0.5 of absorbance in reducing power assay. (B) Minimum inhibitory (MIC) and (C) bactericidal (MBC) concentrations for antibacterial activity of chamomile phenolic compounds extract obtained by decoction $(\boldsymbol{\square})$, and of the standards streptomycin $(\square)$ and ampicillin (-). (D) MIC and minimum fungicidal concentrations (E) (MFC) for antifungal 
activity of chamomile phenolic compounds extract obtained by decoction ( $\mathbf{a})$ and of the standards bifonazole $(\square)$ and ketoconazole $(-)$. The antimicrobial activity results were expressed in $\mathrm{mg} / \mathrm{mL}$ as Mean $\pm \mathrm{SD}(\mathrm{n}=9)$. 

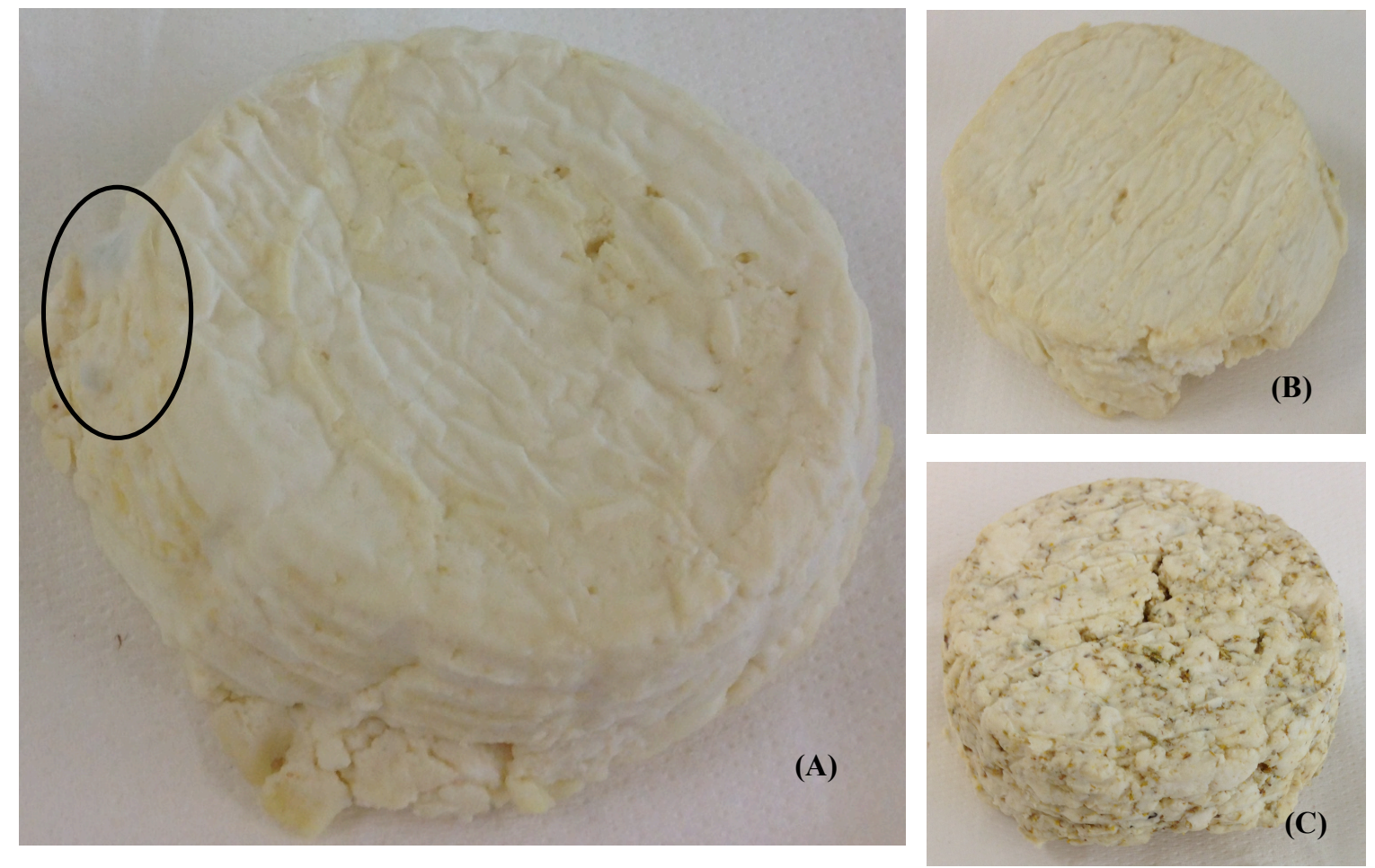

Figure 3. Cottage cheese after 14 days of storage: control sample with signs of degradation (A); sample with chamomile decoction (B) and sample with chamomile powder (C). 